\title{
Le Fort I osteotomy in cleft patients : Maxillary advancement and velopharyngeal function
}

\section{Harjunpää, Roni}

2019-12

Harjunpää , R , Alaluusua , S , Leikola , J \& Heliovaara , A 2019 , ' Le Fort I osteotomy in cleft patients : Maxillary advancement and velopharyngeal function ' , Journal of Cranio-Maxillo-Facial Surgery, vol. 47 , no. 12 , pp. 1868-1874 . https://doi.org/10.1016/j.jcms.2019.11.017

http://hdl.handle.net/10138/327855

https://doi.org/10.1016/j.jcms.2019.11.017

cc_by_nc_nd

acceptedVersion

Downloaded from Helda, University of Helsinki institutional repository.

This is an electronic reprint of the original article.

This reprint may differ from the original in pagination and typographic detail.

Please cite the original version. 


\title{
Le Fort I Osteotomy in Cleft Patients: Maxillary Advancement and Velopharyngeal Function
}

\begin{abstract}
Summary

Background: Maxillary advancement may affect speech in cleft patients.

Aims: To evaluate whether the amount of maxillary advancement in Le Fort I osteotomy affects velopharyngeal function (VPF) in cleft patients.

Methods: Ninety-three non-syndromic cleft patients (51 females, 42 males) were evaluated retrospectively. All patients had undergone a Le Fort I or bimaxillary $(n=24)$ osteotomy at Helsinki Cleft Palate and Craniofacial Center.

Preoperative and postoperative lateral cephalometric radiographs were digitized to measure the amount of maxillary advancement. Pre- and postoperative speech was assessed perceptually and instrumentally by experienced speech therapists. Student's $t$ test and Mann-Whitney's U-test were used in the statistical analyses. Kappa statistics were calculated to assess reliability.

Results: The mean advancement of A point was $4.0 \mathrm{~mm}$ horizontally (range: $-2.8-11.3$ ) and $3.9 \mathrm{~mm}$ vertically (range -14.2-3.9). Although there was a negative change in VPF, the amount of maxillary horizontal or vertical movement did not significantly influence the VPF. There was no difference between the patients with maxillary and bimaxillary osteotomy.

Conclusions: The amount of maxillary advancement does not affect the velopharyngeal function in cleft patients.
\end{abstract}

Keywords: Cleft lip and palate, maxillary advancement, orthognathic surgery, velopharyngeal function, velopharyngeal insufficiency, cephalometrics 


\section{Introduction}

Le Fort I osteotomy is often used in the correction of dental occlusion and maxillary hypoplasia in cleft patients. In addition, the osteotomy may also improve patients' facial appearance and self-esteem. According to the recent literature, 15.6-48.3\% of patients with unilateral cleft lip and palate (UCLP) need orthognathic surgery later (Good et al., 2007; Daskalogiannakis and Mehta, 2009; Heliövaara and Rautio, 2011; Voshol et al., 2012; Dalle Ore et al., 2017). For bilateral cleft lip and palate (BCLP), the percentage is 30-69.6\% (Good et al., 2007; Daskalogiannakis and Mehta, 2009; Voshol et al., 2012; Heliövaara et al., 2013; Dalle Ore et al., 2017). For patients with isolated cleft palate (CP) the need for orthognathic surgery is smaller, 0-13.2\% (Good et al., 2007; Voshol et al., 2012; Antonarakis et al., 2015; Dalle Ore et al., 2017).

When the maxilla is surgically advanced, the hard palate and the attached soft palate are also advanced, which can affect velopharyngeal function (VPF) and speech. The deterioration of VPF may lead to audible nasal emissions and weakness of pressure consonants (Haapanen et al., 1997; Trindade et al., 2003). Previous reports about the effects of maxillary advancement on speech and VPF in patients with clefts are contradictory. Maxillary advancement may affect velopharyngeal function negatively (Haapanen et al., 1997; Janulewicz et al., 2004) or maxillary advancement may not significantly affect VPF (Smedberg et al., 2014; Wu et al., 2015).

Furthermore, in some studies the impairment of VPF has been shown to correlate with the amount of maxillary advancement (Maegawa et al., 1998; Steinberg et al., 1999; Harada et al., 2002) whereas other investigations have found no correlation between the amount of maxillary advancement and VPF (Smedberg et al., 2014; Wu et al., 2015). Several authors have reported a correlation between maxillary advancement and preoperative velopharyngeal function (Steinberg et al., 1999; Alaluusua et al., 2019). In risk are cleft patients with borderline VPF preoperatively. A critical review of the literature found conflicting results about the impact of surgery to velopharyngeal status (Chanchareonsook et al., 2006). According to this review the 39 studies, that were 
included, had used different methods to analyze speech pre- and postoperatively. The conflicting results may be at least partly explained with small sample sizes of separate studies which gives more chance to coincidence.

The purpose of this study was to evaluate whether the amount of maxillary advancement in Le Fort I osteotomy affects VPF in cleft patients. The hypothesis was that a large horizontal maxillary advancement may affect velopharyngeal function more than a small advancement might. In addition, it was evaluated if there is a difference in postoperative VPF between patients with maxillary osteotomy and those with bimaxillary osteotomy.

\section{Materials and methods}

\section{Patients}

This retrospective cohort study examined 93 patients (51 females and 42 males) with non-syndromic cleft lip/palate (CL/P) who underwent Le Fort I maxillary advancement or bimaxillary osteotomy for correction of crossbite and mid-facial retrusion. All patients were operated on at the Cleft Palate and Craniofacial Center, Helsinki University Central Hospital, Finland, between 2002 and 2016. The initial consecutive series consisted of 104 Caucasian patients, but 11 patients were excluded due to five reasons: (1) facial cleft $(n=1),(2)$ maxillary distraction osteotomy $(n=1)$, (3) temporomandibular joint endoprosthesis $(n=1)$, (4) sagittal split osteotomy $(n=1)$, or (5) missing $(n=2)$ or poor-quality radiographs $(n=5)$. The final cohort included 24 patients who had undergone bimaxillary osteotomy. The patient data according to age and cleft type are given in Table 1. 
The mean age of the $\mathrm{CP}$ patients at the time of the operations was 18.3 years (range 13.8-45.3 years); UCLP patients, 17.8 years (range 11.5-28.11 years); and BCLP patients, 18.1 years (range 12.9-27.3).

\section{Surgical methods}

The maxillary osteotomies were performed by three senior cleft surgeons. The osteotomies were grafted using bone from the iliac crest. The bone grafts were interposed in the osteotomy line and fixed with Matrix Orthognathic synthes (DePuy Synthes) or Leibinger Wurzburg miniplates. Prefabricated interocclusal splints were used during the operation. The splints were removed immediately afterward. All patients were given orthodontic treatment before and after the osteotomy. During postoperative orthodontics intermaxillary elastics were used individually for minor corrections of intercuspidation.

During the Le Fort I operation, a simultaneous sagittal split osteotomy was done for 24 patients. Four patients had the osteotomies done during growth because of severe maxillary hypoplasia that caused functional, esthetic, and/or social problems.

All patients had their primary and secondary cleft surgery done in the same cleft center by the same cleft team. In total, 31 patients (9 CP, 13 UCLP, 9 BCLP) underwent corrective speech surgery before undergoing a Le Fort I osteotomy. Among these, 19 patients (6 CP, 7 UCLP, 6 BCLP) had a velopharyngeal flap. Six patients (2 CP, 3 UCLP, 1 BCLP) underwent Furlow's palatoplasty, and 6 (1 CP, 3 UCLP, 2 BCLP) underwent two speech corrective surgeries, Furlow's palatoplasty, and a velopharyngeal flap.

\section{Lateral cephalometric analysis}

Standardized lateral cephalometric radiographs were taken, with the head positioned in alignment with the Frankfort horizontal plane with molar teeth occluded and lips in repose. On average, the radiographs were taken 3.96 months before the operation (standard deviation (SD) 4.41 months) and 8.05 months after the operation (SD 3.21 
months). The cephalograms were traced by the same investigator with the Dolphin cephalometric program (Dolphin Imaging 11.95 Premium) (See Fig. 1). To differentiate between horizontal and vertical changes, the cephalometric program uses an $x-y$ coordinate system. The subsequent cephalometric tracing was superimposed by a SellaNasion ( $\mathrm{SN}$ ) plane. Changes in maxillary position were calculated by changes of value of two cephalometric points, point A (the most concave point of the anterior maxilla) and PNS point (posterior limit of bony maxilla).

In addition, two measurements were used to evaluate the changes in the sagittal pharyngeal airway. Point OP represent the sagittal depth of the oropharynx and point UHP represent the sagittal depth of the upper hypopharynx. All measurements were corrected for cephalometric enlargement.

\section{Speech analysis}

Speech data were reviewed from hospital records by speech therapists. The speech data of the 93 patients had been evaluated preoperatively and 6-12 months postoperatively by experienced speech pathologists working at the Cleft Palate and Craniofacial Center. Analysis was completed both perceptually and instrumentally, using a nasometer (Kay Pentax Nasometer II, model 6400, Kay Elemetrics, USA). A five-point scale was used to assess the degree of velopharyngeal insufficiency (VPI): $0=$ normal velopharyngeal competence; 1 = insignificant, borderline, mild, and occasional VPI detected by ears and/or nasometer; $2=$ mild and consistent VPI; $3=$ moderate and consistent VPI; $4=$ severe and consistent VPI. Cleft speech characteristics generally related to VPI consisted of the assessment of hypernasality, nasal air emissions, and difficulties producing the pressure consonants $(\mathrm{p}, \mathrm{t}$, and $\mathrm{k})$.

To increase reliability, 30 pre- and postoperative video recordings were re-evaluated by two cleft-experienced speech therapists. Intra- and inter-rater agreement was calculated for the completed evaluations. The assessment was done separately in a quiet room where the therapists listened through high-quality headphones (Creative Aurvana Live, Creative Technology Ltd, Singapore). The method of speech evaluation is described in more detail in (Alaluusua et al., 2019). 
All cleft types were pooled for the speech assessment because it has been shown that the type of cleft does not affect the velopharyngeal function after Le Fort I osteotomy (Alaluusua et al., 2019).

\section{Statistical methods}

Student's t-test, Mann-Whitney's U-test, and kappa statistics were used in the statistical analyses. Student's t-test and Mann-Whitney U-test were used to calculate the effect of maxillary advancement on velopharyngeal function and nasopharyngeal airway and to assess the effect of maxillary and bimaxillary osteotomy on VPF. Kappa statistics were calculated to assess the reliability of the cephalometric landmarks and the intra- and interrater reliabilities of the speech evaluations. Reliability for the tracings was determined by re-digitalizing 20 randomly selected cephalograms. The statistical analyses were performed by a statistician.

Results

The amount of maxillary advancement did not affect the velopharyngeal function. The differences were insignificant, both horizontally $(\mathrm{Ax}: \mathrm{T}=-0.0500, \mathrm{p}=0.960 \mathrm{~ns} ; \mathrm{PNSx}$ $\mathrm{Z}=0.0326, \mathrm{p}=0.977 \mathrm{~ns})$ and vertically $($ Ay: $\mathrm{T}=0.6078, \mathrm{p}=0.545 \mathrm{~ns}$; PNSy: $\mathrm{Z}=-$ $0.7297, \mathrm{p}=0.468 \mathrm{~ns})$. There were no differences on VPF between the patients with maxillary and bimaxillary osteotomy $(\mathrm{Z}=-0.6288, \mathrm{p}=0,5295 \mathrm{~ns})$.

In addition, the changes in the pharyngeal airway were not significant for velopharyngeal function $(\mathrm{OP} 1: \mathrm{T}=-0.7433, \mathrm{p}=0.114 \mathrm{~ns} ; \mathrm{OP} 2: \mathrm{T}=-1.0930, \mathrm{p}=$ $0.191 \mathrm{~ns} ;$ UHP 1: $Z=0.1793, p=0.860 \mathrm{~ns}$; UHP 2: $Z=-0.1671, p=0.870 \mathrm{~ns}$ ).

\section{Maxillary advancement}

The average horizontal advancement of point $\mathrm{A}$ in all 93 patients (all cleft types combined) was $4.0 \mathrm{~mm}$, and the average vertical advancement of point $\mathrm{A}$ was $-3.9 \mathrm{~mm}$ 
(Table 2). A positive value of horizontal advancement represents anterior movement and a negative-value posterior movement of the maxilla. In the vertical direction, a positive value represents the movement of the maxilla to a more cranial position and a negative value movement to a more caudal position. The corresponding values of the posterior maxilla were similar in the horizontal direction but smaller in the vertical direction.

The largest mean horizontal advancement of the maxilla (point A) was found in patients with BCLP (4.6 mm). The smallest mean advancement of the maxilla (point A) was found in patients with CP $(3.3 \mathrm{~mm})$, Table 2.

The largest mean vertical advancement of the anterior maxilla (point A) was among patients with BCLP $(-4.2 \mathrm{~mm})$. The smallest mean vertical advancement of the maxilla (point A) was among patients with UCLP $(-3.8 \mathrm{~mm})$, Table 2. A similar trend was found in all cleft types; the vertical movements were smaller in the posterior maxilla.

Pre- and postoperative values of cephalometric angles ANB, SNB and ANB by cleft type and all cleft types combined are given in Table 3. It is noticeable that the values of ANB increased postoperatively in all groups. This reflects the correction of the preoperative maxillomandibular discrepancy.

\section{Changes in the oropharynx and upper hypopharynx}

The mean changes in the pharyngeal airway by cleft type and all cleft types combined are given in Table 4. The changes in the oropharynx or upper hypopharynx were small in all cleft types.

\section{Speech}

There was a negative change in velopharyngeal function after maxillary osteotomy. Preoperatively, 82 patients (88. 2\%) had a normal or insignificant VPI (0-1), 9 patients (9.7\%) had a mild VPI (2) and 2 patients (2.2\%) had a moderate VPI (3). Postoperatively, 70 patients $(75.3 \%)$ had VPI values of $0-1,9$ patients $(9.7 \%)$ had a 
mild VPI (2) and 11 patients (11.8\%) had moderate to severe VPI (VPI 3-4). Pre- and postoperative values of VPI in all cleft patients and values of VPI are shown in Figure 2.

In 14 patients with preoperatively normal VP function, VPI (0), insignificant VPI (1) was noticed postoperatively. In addition, in 3 patients the pharyngeal flap was resected during osteotomy, and increased VPI values (from 0 to 3) were recorded postoperatively. In total, 31 patients had undergone corrective speech surgery before osteotomy. In 19 of these patients, pharyngeal flaps were used. The speech evaluation and the results are described in more detail in (Alaluusua et al., 2019).

\section{Reliability}

Reliability for the tracings was determined by retracing and re-digitalizing radiographs of 20 randomly selected patients from our material. The values of two tracings were compared with Kappa statistics. The reliability varied from fair 0.56 to excellent 0.93 (fair (PNS x) good (PNS y, OP 1) excellent (point A x, point A y, OP 2, UHP 1, UHP 2).

The perceptual re-evaluations completed by two speech pathologists were compared against each other, and the intra- and interrater reliabilities were calculated and found to vary between good and excellent agreement (0.728-0.959 and 0.622-0.842, respectively) (Alaluusua et al., 2019).

\section{Discussion}

Current results suggest that the amount of advancement of the maxilla in Le Fort I surgery does not affect velopharyngeal function in cleft patients. This finding agrees with several previous observations with smaller materials (Watzke et al., 1990; Chanchareonsook et al., 2007; Chua et al., 2010; Smedberg et al., 2014; Impieri et al., 2018). The mean surgical horizontal advancement in our study was moderate $(4.0 \mathrm{~mm})$, although there was large individual variation, and the amount of horizontal maxillary 
advancement varied from -2.8 to $11.3 \mathrm{~mm}$. It has been stated that especially over 10 $\mathrm{mm}$ advancements of the maxilla raise the risk of speech deterioration and that VPI increases with greater advancements of the maxilla (Maegawa et al., 1998). In this investigation of 40 patients with cleft lip and palate, 10 experienced improved speech, 18 demonstrated no detectable changes in speech, and 12 presented with worsened speech intelligibility after maxilla osteotomy. The average amount of maxillary advancement was significantly larger in the group with worsened speech intelligibility $(12.2 \mathrm{~mm})$ than in the two other groups $(9.4 \mathrm{~mm})$. It has been stated that patients with borderline velopharyngeal closure may demonstrate velopharyngeal insufficiency following maxillary advancement particularly if the advancement exceeds $10 \mathrm{~mm}$ (Epker and Wolford, 1976). In contrast, it has been concluded that maxillary advancements less than $15 \mathrm{~mm}$ not compromise velopharyngeal function (Harada et al., 2002). However, in this investigation authors studied postoperative changes of velopharyngeal function in six cleft patients who underwent external maxillary distraction osteogenesis.

As majority of the cleft patients have deficient midfacial height, there is an essential need to not only to advance the maxilla but also reposition the maxilla downwards in order to increase the vertical midfacial height. The mean anterior vertical lengthening in our study was $3.9 \mathrm{~mm}$ (point A) whereas the mean posterior lengthening was only 0.7 $\mathrm{mm}$ (point PNS) although the individual variation was large. It is of clinical importance that neither the amount of horizontal advancement nor the amount of vertical lengthening did affect VPF.

Only a few papers have assessed maxillary and bimaxillary surgery and VPF. Interestingly no significant differences in VPF between these groups were noticed in our study. This is in an agreement with previous results (Janulewicz et al., 2004). In contrast, it has been noted that bimaxillary surgery seems to be protective against worsening of VPI and sagittal split setback appearing to have a strong association with speech improvement (Maegawa et al., 1998; Impieri et al., 2018). 
Some authors have found a positive correlation between the amount of maxillary advancement and the increase in nasopharyngeal depth and hypernasality (Taha and Elsheikh, 2016). The study evaluated early and late velopharyngeal changes in $30 \mathrm{cleft}$ lip and palate patients after use of the rigid external distractor (RED) device. In an investigation of 47 patients with cleft lip and palate, authors found a significant increase (mean increase $4.66 \mathrm{~mm} \pm 2.61 \mathrm{~mm}$ ) of nasopharyngeal depth (at the level of the palatal plane) after maxillary osteotomy (Wu et al., 2015). In the study mean maxillary advancement was $4.08 \pm 1.58 \mathrm{~mm}$, which is similar as in our study. However, authors found no significant changes of oropharyngeal depth (at the level of the uvula). We found only minor soft-tissue pharyngeal changes after maxillary advancement. The explanation for the different results may be at least partly due to the differences in the cephalometric points. Our measurement points UPH (upper pharynx) and OP (oropharynx) were measured from a lower level of the nasopharynx and oropharynx. These findings are supported by the previous finding by (Heliövaara et al., 2004). One year after maxillary osteotomy there was a significant change in the depth of nasopharyngeal airway but not in the depth of the oropharyngeal airway (at the level of the uvula or gonion) in 50 patients with different types of clefts.

A critical review of 39 published articles stated that studies of the effect of maxillary advancement on VP status have reported mixed results, and the correlation between the amount of maxillary advancement and velopharyngeal deterioration seems unclear (Chanchareonsook et al., 2006). The review also stated that from the 36 studies $(61 \%)$ that specified their method of assessment, 22 used a combination of perceptual speech analysis and instrumental techniques. Some proposals have been made to create minimal standards for reporting the results of surgeries' effect on speech in patients with cleft lip and palate. Assessment and reporting of resonance (hypernasality, hyponasality), articulation, nasal emission, and the use of at least one instrumental measure (nasendoscopy, multi-view videofluoroscopy, nasometry, or pressure-flow) is necessary to evaluate velopharyngeal function (Dalston et al., 1988). In our study, we 
analyzed speech pre- and postoperatively, both perceptually and instrumentally, using a nasometer, which served to validate the perceptual assessment.

It has been concluded that maxillary advancement can trigger or worsen VPI, especially in cleft patients. There have been an observation of a significant increase in mean nasalance score and other significant deterioration in velopharyngeal function and symptoms of VPI with perceptual speech assessments after maxillary advancement (Trindade et al., 2003; Janulewicz et al., 2004; Pereira et al., 2013). An increase in the cross-sectional area of the velopharyngeal port has been noticed after maxillary advancement on 15 cleft patients (Haapanen et al., 1997). This indicated some risk for VPI. In contrast, it has been stated that repaired cleft palate patients without preoperative velopharyngeal dysfunction do not face greater risk of velopharyngeal function impairment after maxillary advancement than non-cleft palate patients (Kim et al., 2012). However, it has been showed with this same material that the postoperative VPF correlates with preoperative velopharyngeal function in cleft patients (Alaluusua et al., 2019). At-risk patients presented with borderline (1) or more severe VPI (2 and 3) preoperatively (Alaluusua et al., 2019). The velopharyngeal changes seen immediately after osteotomy on patients with CLP were stable and permanent with no significant differences from controls at 3 and 12 months after surgery (Pereira et al., 2013). In the current study, the postoperative cephalograms were taken, on average, 8.05 months (SD: 3.21 months) after the maxilla osteotomy.

The results so far seem contradictory, which could partly be due both to methodological differences for outcome analysis and to differences in the variety of length of advancement in the studies. In addition, many studies investigating this topic, have had relatively small sample sizes which gives more chance to coincidence. It should also be noted that there may be great variation in anatomy between cleft patients, depending on cleft type and severity and on previous surgical operations, such as pharyngeal flaps. Moreover, gender, age, and race may vary considerably between patients in different study groups. Witzel pointed out in the commentary section that it must be noted that Le Fort I osteotomy does not provide an accurate description of how an operation itself is 
performed (Kummer et al., 1989). She also stated that, "The philosophies, treatments and goals, as well as the surgical techniques, will vary from team to team and even among team members. The results from one center may not correspond to the results from another center".

The strength of the current study was that our cohort consisted of almost one hundred patients with clefts who were operated on by three experienced senior surgeons from the same Cleft Center.

The limitations include subjectivity of the cephalometric digitations and speech assessment. Although we determined the reliabilities for cephalometric landmarks, the method error becomes more critical when small surgical changes are evaluated. The reliabilities were also tested for the speech analyses.

We used perceptual evaluation and Nasometer tests to assess speech. The gold standard for evaluation of speech would have been perceptual speech analysis, acoustic measurement with Nasometer and visual perceptual assessment with videofluorography (VF) and videonasoendoscopy (VNE) (Pereira et al., 2013). However, according to (Smedberg et al. 2014) perceptual speech assessment from standardized audio recordings and nasometry might be sufficient for examination of a typical cleft patient. A selected combined approach could be suggested, including a visualization technique for examination of the VPF, in patients with syndromes/additional malformations (Smedberg et al., 2014). Most studies on maxillary advancement and speech have used perceptual analysis alone which may partially explain the controversy of the speech results (Chanchareonsook et al., 2006).

Furthermore, the patients of this study varied with regard to type of cleft, and technique of primary and secondary surgery. In total, 31 patients had undergone corrective speech surgery before osteotomy. Unfortunately, the material was too small for statistical evaluation of differences between cleft types and preoperative speech surgery. 


\section{Conclusion}

Patients with clefts should be informed preoperatively that they might have to undergo additional speech surgery after maxillary osteotomy. Le Fort 1 osteotomy may have a negative effect on velopharyngeal function in cleft patients, but this is not related to the amount of maxillary advancement.

\section{Conflict of interest}

The authors declare no conflicts of interest.

\section{Ethical approval}

The study protocol was approved by Helsinki University Hospital and adhered to the principles outlined in the declaration of Helsinki.

\section{Funding}

Apollonian apuraha 200 


\section{References}

Alaluusua S, Turunen L, Saarikko A, Geneid A, Leikola J, Heliövaara A: The effects of Le Fort I osteotomy on velopharyngeal function in cleft patients. Surg 47:239-244, 2019.

Antonarakis G, Watts G, Daskalogiannakis J.: The need for orthognathic surgery in nonsyndromic patients with repaired isolated cleft palate. Cleft Palate Craniofac J 52:813, 2015.

Chanchareonsook N, Samman N, Whitehill T: The effect of cranio-maxillofacial osteotomies and distraction osteogenesis on speech and velopharyngeal status: a critical review. Cleft Palate Craniofac J 43:477-487, 2006.

Chanchareonsook N, Whitehill T, Samman N: Speech outcome and velopharyngeal function in cleft palate: comparison of Le Fort I maxillary osteotomy and distraction osteogenesisearly results. Cleft Palate Craniofacial J 44:23-32, 2007.

Chua H, Whitehill T, Samman N, Cheung L: Maxillary distraction versus orthognathic surgery in cleft lip and palate patients: effects on speech and velopharyngeal function. Int J Oral Maxillofac Surg 39:633-640, 2010.

Dalle Ore C, Schoenbrunner A, Brandel M, Kronstadt N, McIntyre J, Jones M, Gosman A: Incidence of Le Fort Surgery in a Mature Cohort of Patients With Cleft Lip and Palate. Ann Plast Surg 78:199-203, 2017.

Dalston R, Marsh J, Vig K, Witzel M, Bumsted R: Minimal standards for reporting the results of surgery on patients with cleft lip, cleft palate, or both: a proposal. Cleft Palate J 25:37, 1988.

Daskalogiannakis J, Mehta M: The need for orthognathic surgery in patients with repaired complete unilateral and complete bilateral cleft lip and palate. Cleft Palate Craniofac J 46:498-502, 2009.

Epker BN, Wolford LM: Middle-third facial osteotomies: their use in the correction of congenital dentofacial and craniofacial deformities. J Oral Surg 34:324-342, 1976.

Good P, Mulliken J, Padwa B: Frequency of Le Fort I osteotomy after repaired cleft lip and palate or cleft palate. Cleft Palate Craniofac J 44:396-401, 2007.

Haapanen M, Kalland M, Heliövaara A, Hukki J, Ranta R: Velopharyngeal function in cleft patients undergoing maxillary advancement. Folia Phoniatr et Logop 49:42-47, 1997.

Harada K, Ishii Y, Ishii M, Imaizumi H, Mibu M, Omura K: Effect of maxillary distraction osteogenesis on velopharyngeal function: a pilot study. Oral Surg Oral Med Oral Pathol Oral Radiol Endod 93:538-543, 2002. 
Heliövaara A, Hukki J, Ranta R, Haapanen M: Cephalometric pharyngeal changes after Le Fort I osteotomy in different types of clefts. Scand J Plast Reconstr Surg Hand Surg 38:5$10,2004$.

Heliövaara A, Leikola J, Hukki J: Craniofacial cephalometric morphology and later need for orthognathic surgery in 6-year-old children with bilateral cleft lip and palate. Cleft Palate Craniofac J 50:e35-40, 2013.

Heliövaara A, Rautio J: A comparison of craniofacial cephalometric morphology and the later need for orthognathic surgery in 6-year-old cleft children. J Craniomaxillofac surg 39:173-176, 2011.

Impieri D, Tønseth KA, Hide Ø, Brinck EL, Høgevold HE, Filip C: Impact of orthognathic surgery on velopharyngeal function by evaluating speech and cephalometric radiographs. J Plast Reconstr Aesthet Surg, 71:1786-1795, 2018.

Janulewicz J, Costello B, Buckley M, Ford M, Close J, Gassner R: The effects of Le Fort I osteotomies on velopharyngeal and speech functions in cleft patients. J Oral Maxillofac Surg 62:308-314, 2004.

Kim S-K, Kim J-C, Moon J-B, Lee K-C: Perceptual Speech Assessment after Maxillary Advancement Osteotomy in Patients with a Repaired Cleft Lip and Palate. Arch Plast Surg 39:198-202, 2012.

Kummer AW, Strife JL, Grau WH, Creaghead NA, Lee L: The effects of Le Fort I osteotomy with maxillary movement on articulation, resonance, and velopharyngeal function. Cleft Palate J 26:193-200, 1989.

Maegawa J, Sells RK, David DJ: Speech changes after maxillary advancement in 40 cleft lip and palate patients. J Craniofac Surg 9:177-182; discussion 183-184, 1998.

Pereira VJ, Sell D, Tuomainen J: Effect of maxillary osteotomy on speech in cleft lip and palate: perceptual outcomes of velopharyngeal function. Int J Lang Commun Disord 48:640-650, 2013.

Smedberg E, Neovius E, Lohmander A: Impact of maxillary advancement on speech and velopharyngeal function in patients with cleft lip and palate. Cleft Palate Craniofac J 51:334-343, 2014.

Steinberg B, Padwa BL, Boyne P, Kaban L: State of the art in oral and maxillofacial surgery: treatment of maxillary hypoplasia and anterior palatal and alveolar clefts. Cleft Palate Craniofac J 36:283-291, 1999.

Taha M, Elsheikh YM: Velopharyngeal changes after maxillary distraction in cleft patients using a rigid external distraction device: A retrospective study. Angle Orthod 86:962968, 2016. 
Trindade IE, Yamashita RP, Suguimoto RM, Mazzottini R, Trindade AS Jr: Effects of orthognathic surgery on speech and breathing of subjects with cleft lip and palate: acoustic and aerodynamic assessment. Cleft Palate Craniofac J 40:54-64, 2003.

Voshol IE, Wal KGH van der, Adrichem LNA van, Ongkosuwito EM, Koudstaal MJ: The frequency of Le Fort I osteotomy in cleft patients. Cleft Palate Craniofac J 49:160-166, 2012.

Watzke I, Turvey TA, Warren DW, Dalston R: Alterations in velopharyngeal function after maxillary advancement in cleft palate patients. J Oral Maxillofac Surg 48:685-689, 1990.

Wu Y, Wang X, Ma L, Li Z: Velopharyngeal Configuration Changes Following Le Fort I Osteotomy With Maxillary Advancement in Patients With Cleft Lip and Palate: A Cephalometric Study. Cleft Palate Craniofac J 52:711-716, 2015. 
Table 1. Patients by cleft type and gender

\begin{tabular}{llcc}
\hline Cleft type & Males & Females & Total \\
\hline CP / SMCP & 7 & 18 & 25 \\
\hline UCLP & 25 & 21 & 46 \\
\hline BCLP & 10 & 12 & 22 \\
\hline Total & 42 & 51 & 93 \\
\hline
\end{tabular}


Table 2. Horizontal and vertical advancements by cleft type and all cleft types combined (mm).

\begin{tabular}{|c|c|c|c|c|c|c|}
\hline & \multicolumn{3}{|c|}{ Horizontal advancements (mm) } & \multicolumn{3}{|c|}{ Vertical advancements (mm) } \\
\hline & Landmark name & Point A & PNS & Landmark name & Point A & PNS \\
\hline \multirow[t]{3}{*}{ UCLP } & Mean & 4.1 & 4.1 & Mean & -3.8 & -0.8 \\
\hline & Range & $-2.8-11.3$ & $-4.3-14.0$ & Range & $-14.2-3.9$ & $-13.0-7.2$ \\
\hline & $\mathrm{SD}$ & 3.5 & 3.8 & SD & 3.7 & 3.2 \\
\hline \multirow[t]{3}{*}{ BCLP } & Mean & 4.6 & 5.0 & Mean & -4.2 & 0.0 \\
\hline & Range & $-0.9-10.4$ & $1.0-13.2$ & Range & $-8.8-2.8$ & $-3.5-2.6$ \\
\hline & SD & 3.0 & 3.0 & SD & 3.2 & 1.8 \\
\hline \multirow[t]{3}{*}{$\mathbf{C P}$} & Mean & 3.3 & 3.2 & Mean & -3.9 & -1.1 \\
\hline & Range & $-0.1-9.8$ & $-0.1-10.5$ & Range & $-8.5-0.6$ & $-5.3-4.1$ \\
\hline & $\mathrm{SD}$ & 2.9 & 2.6 & $\mathrm{SD}$ & 2.8 & 2.2 \\
\hline \multirow{2}{*}{$\begin{array}{l}\text { All cleft types } \\
\text { combined }\end{array}$} & Mean & 4.0 & 4.1 & Mean & -3.9 & -0.7 \\
\hline & Range & $-2.8-11.3$ & $-4.3-14.0$ & Range & $-14.2-3.9$ & $-13.0-7.2$ \\
\hline & SD & 3.2 & 3.4 & SD & 3.4 & 2.7 \\
\hline
\end{tabular}


Table 3. Pre- and postoperative values of cephalometric angles ANB, SNB and ANB by cleft type and all cleft types combined ( $\square$ ).

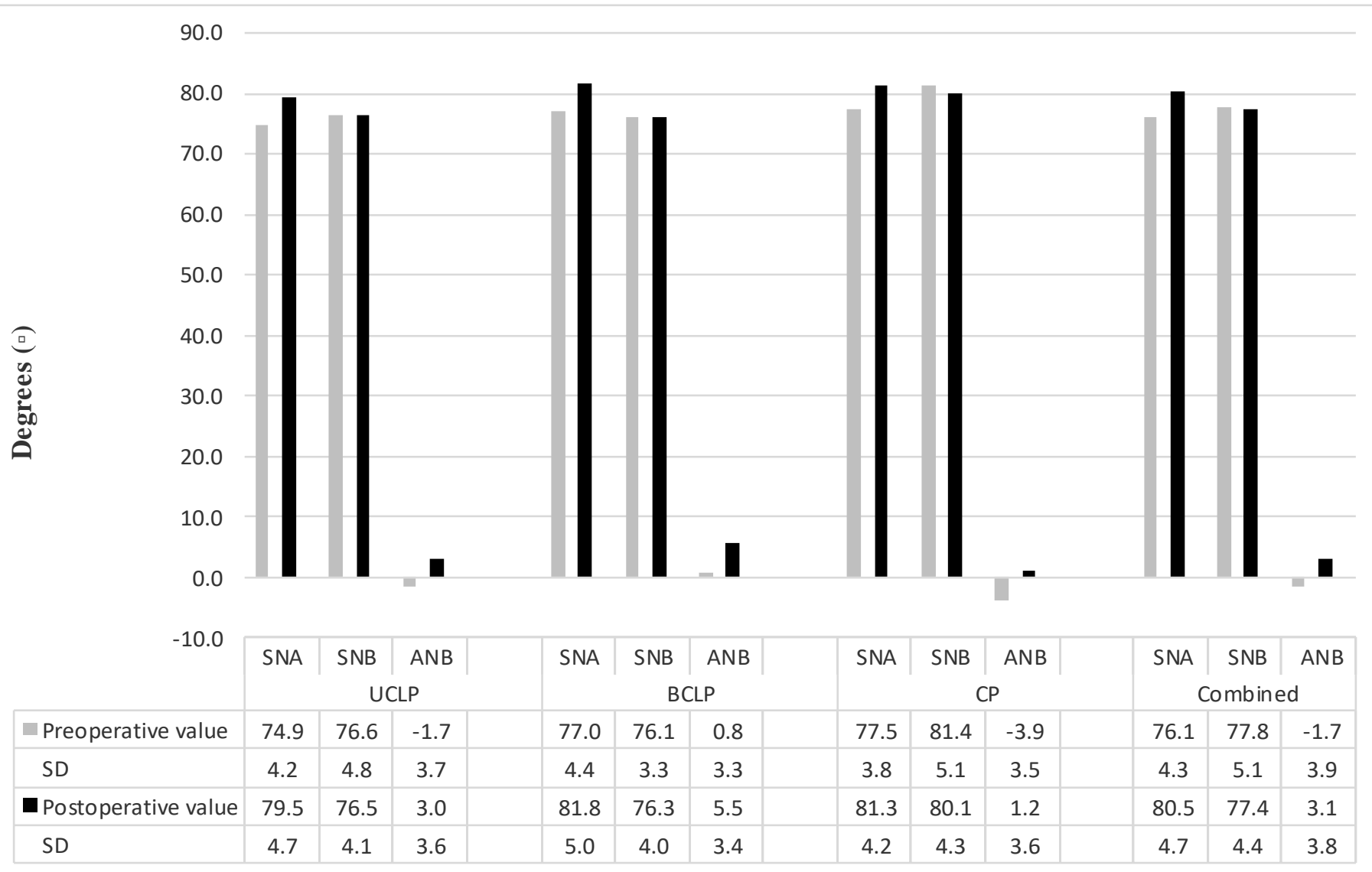


Table 4. The mean horizontal measurements of oropharynx and upper hypopharynx by cleft type and all clefts combined (mm).

\begin{tabular}{|c|c|c|c|c|c|}
\hline Cleft type & $\begin{array}{l}\text { Landmark } \\
\text { name }\end{array}$ & Pre-op & Post-op & $\begin{array}{l}\text { Upper } \\
\text { hypopharynx } \\
\text { Pre-on }\end{array}$ & $\begin{array}{l}\text { Upper } \\
\text { hypopharynx } \\
\text { Post-on }\end{array}$ \\
\hline \multirow[t]{3}{*}{ UCLP } & Mean & 15.7 & 16.9 & 11.4 & 11.1 \\
\hline & Range & $5.0-24.5$ & $6.3-23.3$ & $4.4-25.5$ & $3.7-23.3$ \\
\hline & SD & 3.9 & 3.7 & 4.4 & 4.3 \\
\hline \multirow[t]{3}{*}{ BCLP } & Mean & 16.5 & 16.5 & 10.9 & 10.7 \\
\hline & Range & $8.4-24.9$ & $8.6-23.6$ & $5.1-20.5$ & $5.5-17.8$ \\
\hline & SD & 4.6 & 4.1 & 3.1 & 2.8 \\
\hline \multirow[t]{3}{*}{$\mathbf{C P}$} & Mean & 15.3 & 16.0 & 11.4 & 10.6 \\
\hline & Range & $7.4-22.7$ & $8.7-23.4$ & $5.9-24.0$ & $7.0-17.5$ \\
\hline & SD & 3.3 & 3.1 & 4.0 & 2.7 \\
\hline \multirow[t]{3}{*}{$\begin{array}{l}\text { All cleft } \\
\text { combined }\end{array}$} & Mean & 15.8 & 16.6 & 11.3 & 10.9 \\
\hline & Range & $5.0-24.9$ & $6.3-23.6$ & $4.4-25.5$ & $3.7-23.3$ \\
\hline & SD & 3.9 & 3.7 & 4.0 & 3.6 \\
\hline
\end{tabular}


Captions to illustrations

Figure 1. The cephalometric landmarks with full names and definitions. A (point A): the most concave point of anterior maxilla; B (point B): deepest point on the anterior contour of the mandibular alveolar arch; $\mathbf{N}$ (nasion): the most anterior point on the nasofrontal suture; OP (oropharynx): sagittal depth of oropharynx at level of the most convex part of atlas vertebra, point a represents posterior wall of the oropharynx and point $\mathbf{b}$ represents anterior wall. OP $\mathbf{1}$ is preoperative sagittal depth and OP $\mathbf{2}$ is postoperative sagittal depth; PNS (posterior nasal spine): posterior limit of bony maxilla; $\mathbf{S}$ (sella): center of sella turcica; UHP (upper hypopharynx): sagittal depth of pharynx at the same vertical level as B-point. UHP 1 is preoperative sagittal depth and UHP 2 is postoperative sagittal depth. Point a represents posterior wall of the hypopharynx and point $\mathbf{b}$ represents anterior wall.

Figure 2. Pre- and postoperative VPI values in 93 cleft patients (46 UCLP, 22 BCLP, and $25 \mathrm{CP} / \mathrm{SMCP}$. Dark green referring to normal velopharyngeal competence (VPI 0), light green to insignificant (VPI 1), yellow to mild and consistent (VPI 2), orange to moderate (VPI 3) and red to severe (VPI 4). 